\title{
Effectiveness of In-Store Displays in a Virtual Store Environment
}

\author{
Els Breugelmans ${ }^{1}$ \\ Lessius University College - Catholic University of Leuven Association
}

Katia Campo

Catholic University of Leuven - Lessius University College

August 2010

Published as: E. Breugelmans and K. Campo (2011), "Effectiveness of In-Store Displays in a Virtual Store Environment," Journal of Retailing, 87 (1), 75-89.

\section{Acknowledgments}

The authors thank an anonymous online grocery retailer for providing the data used in this study.They further thank Bram Foubert, Els Gijsbrechts, Michael Trusov, the three anonymous reviewers and the editors for their helpful suggestions on previous versions of this article.

\footnotetext{
${ }^{1}$ Corresponding Author: Els Breugelmans is Assistant Professor at the School of Business of Lessius University College and Affiliate Researcher in Marketing at the Faculty of Business and Economics of the Catholic University of Leuven. Address: Korte Nieuwstraat 33, 2000 Antwerp, Belgium. Tel.+32-32011882. E-mail: els.breugelmans@lessius.eu

Katia Campo is Professor of Marketing at the Faculty of Business and Economics of the Catholic University of Leuven and at the School of Business of Lessius University College. Address:

Naamsestraat 69, 3000 Leuven (Belgium). Tel. +3216326819. E-mail: katia.campo@econ.kuleuven.be
} 


\title{
Effectiveness of In-Store Displays in a Virtual Store Environment
}

\begin{abstract}
This article examines in-store display (ISD) effectiveness in an online grocery store and concentrates on two main issues. First, considering the more artificial and functional virtual store environment, we examine whether online ISD produce a similar boost in sales as they do in offline stores. Second, we examine the moderating effect of display characteristics by comparing the effects of different display types. The results show that (1) online ISD can substantially increase brand sales and (2) ISD that preempt competition through a first-order and isolated position outperform ISD that attempt to make the product stand out in the shopping zone.
\end{abstract}

Keywords: in-store displays; online retailing; online grocery shopping; market share models 
In-store displays (ISD) are frequently used in brick-and-mortar (B\&M) stores to bring products to the attention of potential customers. Several studies have provided strong empirical evidence that by drawing attention to specific products, ISD can substantially increase brand sales (Bemmaor and Mouchoux 1991; Dhar, Hoch, and Kumar 2001; East, Eftichiadou, and Williamson 2003; McKinnon, Kelly, and Doyle 1981; Wilkinson, Mason, and Paskoy 1982). With the same objective, displays in online grocery stores, such as promotional signs or in-store ads that highlight specific products to stimulate their sales, are gaining popularity (e.g., www.netgrocer.com, www.peapod.com, www.tesco.com; Appendix A presents the displays used in this study). Online stores can not only benefit from lower costs and more flexibility with regard to ISD on their Web site (e.g., they can change the content with just a few mouse clicks), they also have the opportunity to take advantage of targeted, one-to-one marketing (e.g., displays customized according to each customer's prior purchase history) (Bakos 2001; Zhang and Krishnamurthi 2004).

Whether such ISD effectively increase brand sales in online stores has not yet been examined, nor is the answer clear in advance. On the one hand, there are indications that online shoppers may react differently to specific marketing mix instruments, such as price and brand name, and that they are less likely to switch brands in response to marketing incentives compared to offline shoppers (e.g., Andrews and Currim 2004; Chu, Chintagunta, and Cebollada 2008; Degeratu, Rangaswamy, and Wu 2000; Laroche et al. 2005). On the other hand, several studies demonstrate that online shoppers can be equally susceptible to the influence of environmental in-store stimuli, and their product attention may depend on online merchandising instruments, such as shelf space and position (e.g., Breugelmans, Campo, and Gijsbrechts 2007; Vrechopoulos et al. 2004). Therefore, it remains uncertain whether the positive effects of ISD in a B\&M store will also be attained in an online store. 
In addition to the overall effectiveness of online ISD, we also know little about the factors that determine their effectiveness. Better insight into the moderating factors of ISD could improve our understanding of how displays work and offer useful guidelines to retailers and manufacturers for developing in-store marketing plans (Grewal and Levy 2007). In this research, we focus on the moderating effect of display characteristics and examine differences in the effectiveness of display types that differ in their attention- and competition-related features. Some displays try to catch shoppers' attention at the start of the shopping process and preempt competition by taking up a first-order, isolated position; others focus on making the product stand out on the cluttered shelf to influence the purchase decisions of customers by providing the right cue at the right time and place. The online environment — which systematically records all marketing actions, including the type of display—offers an ideal setting for determining which display strategy is most effective.

To shed more light on these issues, we first test whether ISD stimulate brand sales in a virtual shopping context by estimating a hierarchical brand market share and category sales model using data from a large online grocery store. In addition, to gain insight into the most effective display type with regard to increasing brand sales, we examine differences across three major online display types that serve distinct objectives and differ on important attention- and competition-related characteristics. In line with traditional B\&M classifications, we distinguish between store entrance (first screen), aisle, and shelf tag displays. We use our estimated models to test the significance of the different display effects and compare their magnitude across display types. To increase the external validity of the results and test for potential category-specific effects, we also examine effects of ISD for ten different fast moving consumer goods (FMCG) categories.

Our results show that ISD can substantially increase brand market share in online stores, and that their effectiveness strongly depends on the display type. Online ISD that 
preempt competition through a first-order and isolated position clearly outperform those that target interested buyers in the shopping zone. Overall, we find a high degree of consistency in the results across the ten investigated FMCG categories. Our study contributes to the marketing and retailing literature in several ways. We fill an important gap in the online shopping literature by examining the online effectiveness of an in-store marketing instrument that is highly effective in offline settings but that has received little attention thus far in online research. We show that at least some online grocery shoppers are susceptible to influences from the virtual store environment. In addition, our research makes an important contribution to the in-store marketing literature in general by clarifying and testing differential effectiveness across display types that differ in their characteristics and strategy. The advantages of preempting competition by being early in the shopping process consistently seem to dominate the possible advantages of targeting shoppers at the specific time and place they make their choices.

Identifying and understanding the overall effectiveness of online ISD, as well as the impact of strategic display characteristics, is of crucial importance for effective planning of marketing actions — not just for manufacturers that must decide on the mix of in-store incentives but also for retailers that have to determine a cost structure and allocation of display space to different display types (Ailawadi et al. 2009). Our research thus provides useful guidelines to optimize the use of online ISD (Grewal and Levy 2007, 2009).

In the next section, we discuss and derive propositions about the overall effectiveness of ISD in an online grocery shopping context, as well as differences in effectiveness across display types. Next, we describe the empirical setting and models we use to test our propositions. After presenting the main results, we end with a discussion of conclusions and managerial implications, as well as interesting directions for further research. 


\section{EFFECTIVENESS OF ONLINE ISD}

\section{Overall Effectiveness of ISD in an Online Shopping Context}

The main mechanism underlying effects of ISD consists of an increase in visual attention at the point of purchase (Chandon et al. 2009). Displays highlight specific products, such as by adding signals or marks (e.g., tags), changing the presentation layout (e.g., special storage method), or presenting the product in a different, often more isolated area of the shelf or store (e.g., end-of-aisle displays). According to psychological and consumer behavior literature, these changes in the store environment attract attention and stimulate exploratory behavior (e.g., Babin and Darden 1995; Donovan and Rossiter 1982). In addition, many customers seem to interpret ISD as signals or cues of a good deal (Inman, McAlister, and Hoyer 1990). In low involvement, repeat buying situations, such as grocery purchases, these cues tend to increase a displayed product's purchase probability, because customers do not want to go through a complete search and evaluation procedure but instead prefer to settle for satisfying outcomes obtained with minimum effort (Hoyer and MacInnis 2010). Whether ISD have similar positive effects on product sales in online stores thus depends on the extent to which they attract customer attention and signal a good deal, as well as the characteristics of the online shopper segment, including its sensitivity to environmental incentives and cues in a more organized and "sterile" virtual store environment.

We expect ISD to have similar attention-drawing and signaling effects in online as in offline grocery stores for several reasons. Most online grocery stores offer large assortments, a wide variety of choice alternatives, and extensive product and promotional information, so online shoppers tend to confront a sense of information overload similar to that faced by B\&M shoppers. Online ISD that highlight specific products change the store environment and thus may play an important role in attracting customer attention and stimulating exploratory 
behavior. In addition, online ISD may signal a good deal, just as in an offline store, which reinforces the attention-catching effect.

As online grocery shoppers display similar low involvement and time constraints as B\&M shoppers (Verhoef and Langerak 2001), they should also experience the need to simplify their decision process using choice heuristics or cues (Hoyer and MacInnis 2010). The extent to which they rely on ISD as a choice tactic or react to them also depends on their sensitivity to store environment influences and their willingness to change purchase plans. Previous research distinguishes two groups of consumers who differ in their self-regulation tendency and sensitivity to environmental stimuli (Babin and Darden 1995). Action-oriented consumers are guided more by intrinsic goals and less prone to emotional and environmental influences. They are characterized by a stronger tendency to plan their behavior in advance and follow these preformed intentions rather than change their behavior in response to environmental incentives (Babin and Darden 1995). State-oriented consumers instead are more guided by social and emotional elements and less likely to plan their behavior in advance. They often act without prior justification (e.g., decide on the spot), engage in exploratory behavior, and change their purchase plans in reaction to environmental incentives (Babin and Darden 1995).

An important question therefore is whether online grocery stores attract both types of shoppers, as do offline stores, or mainly appeal to a specific shopper segment. Because shopping convenience and time savings are two key advantages of online grocery stores, they may especially appeal to shoppers with a more utilitarian shopping attitude (Prud'homme and Boyer 2005; Verhoef and Langerak 2001). Arnold and Reynolds (2009) demonstrate that selfregulation tendency relates to a consumer's focus on utilitarian versus hedonic shopping value, such that consumers who tend to plan more carefully and try to control environmental 
influences are more oriented toward a utilitarian shopping value. If online stores attract such utilitarian consumers, ISD may have no or a weaker effect on product sales in online stores.

Yet more recent evidence suggests that there are no longer systematic differences between on- and offline shopper profiles and that both groups of shoppers comprise similar subsegments (e.g., Chu et al. 2008; Ganesh et al. 2010). This convergence may be a result of a general increase in popularity of the online purchase channel, which has been adopted by a large part of the population (Kukar-Kinney, Ridgway, and Monroe 2009; Konus, Verhoef, and Neslin 2008). Simultaneously, online grocery stores have evolved from rudimentary, functional sites with verbal product information and limited in-store marketing stimuli (e.g., Degeratu et al. 2000) to stores with extensive visual information (e.g., product pictures), instore incentives (e.g., ISD), and experiential features aimed at enhancing the hedonic shopping experience (e.g., recipes, product preparation videos) (Childers et al. 2001; Laroche et al. 2005). Previous research demonstrates that consumers appreciate these hedonic online features (Childers et al. 2001; Schröder and Zaharia 2008), such that online stores attract a substantial portion of hedonically oriented shoppers (Ganesh et al. 2010; Konus et al. 2008).

Overall then, ISD may perform similar attention-catching and signaling roles in online as in offline grocery stores, and at least part of the online grocery shoppers are sensitive to instore incentives. Therefore, we expect:

Proposition 1: Online ISD have a positive effect on sales of the displayed product. Differences in Effectiveness between In-Store Display Types

In addition to the overall effectiveness of online ISD, we consider potential moderating factors. Differences in display effectiveness across display types are well recognized in commercial applications (e.g., www.instoremarketer.org, www.popai.com; Liljenwall 2004; Spaeth 2004), but few academic articles systematically investigate the effect of different display types. In both off- and online stores, different types can be distinguished 
by their location in the store. The importance of location as a distinguishing moderating characteristic of promotion effectiveness was stressed by Drèze and Hoch (1998) in their study of cross-category promotion effects. For ISD in B\&M stores, a classification based on location distinguishes among entrance, end-of-aisle, and shelf displays (e.g., Tellis 1998). Translated to an online context, a similar location-based classification would consist of (i) first screen, (ii) aisle, and (iii) shelf tag displays, as we detail in Appendix A using graphical examples.

The three locations correspond to different store zones that have distinct functions, such as zones used for traveling (store and aisle entrances) and zones used more for shopping (shelf area within the aisle) (e.g., East et al. 2003; Larson, Bradlow, and Fader 2005). The display location relates closely to the order of appearance: First screen displays typically are encountered first, followed by aisle and shelf tag displays. In addition, displays in traveling and shopping zones differ in visibility (determined by size and onscreen position) and amount of exclusivity (number of simultaneously displayed ads). That is, first screen and aisle displays tend to be larger and more exclusive because of their isolated position, whereas shelf tag displays are usually small and presented simultaneously with several other displays. Finally, the displays also differ in whether they offer an immediate purchase opportunity or not. First screen displays and shelf tags contain a 'buy button' that customers can use to place the featured stockkeeping unit (SKU) (i.e., a specific type, flavor, and/or package size of the brand) immediately into their shopping basket. Aisle displays, in contrast, do not offer a direct buying option, but re-direct consumers after clicking on the display to a list with all SKUs of the featured brand.

As a result of these differences, the three types of ISD may affect purchase behavior in substantially different ways and serve distinct targeting and competitive objectives. The major objective of first screen displays is to preempt competition from alternative offers (i.e., both 
other products and displays) by intercepting customers before they even reach the shopping zone and by offering an immediate purchase opportunity. By eliciting a direct buying reaction, they aim to exclude alternatives from the evaluation process (primacy effect; $\mathrm{Xu}$ and Hee-Woong 2008). Conversely, shelf tag displays target customers who demonstrate their interest in the product category (visit the product category page) and attempt to influence their choice at the moment of the purchase decision, by highlighting a specific product among the many alternatives displayed in the same shopping zone. Both preempting and targeting objectives can be served by aisle displays. They are more exclusive than shelf tag displays, because they offer a somewhat isolated (border-screen) position to feature a brand and redirect consumers to an exclusive list with the brand's SKUs (preempting objective). At the same time, they reach customers whose attention is already focused on the category since they are entering the shopping zone location (targeting objective).

Which strategy is most effective_-preempting competition or targeting interested buyers - may depend on the consumer's overall sensitivity to in-store incentives. As indicated previously, we expect small or insignificant effects of ISD for utilitarian-oriented customers who pay less attention to environmental cues and are reluctant to change their purchase plans in response to in-store incentives. This tendency may especially reduce the effectiveness of preemption oriented first screen displays, which create several disadvantages for utilitarianoriented customers. In particular, these displays may require a greater change in purchase behavior, because customers encounter them before entering the shopping zone and their attention may not be focused on making a purchase in the category yet. Moreover, these displays do not allow for a direct and detailed comparison of the displayed product with alternative items in the assortment, which complicates the evaluation and risks a loss in utilitarian value (Arnold and Reynolds 2009; Delvecchio, Lakshmanan and Krihnan 2009). 
In contrast, customers with a hedonic shopping attitude are more susceptible to influences from the store environment and more willing to engage in exploratory behavior and adjust their purchase plans. Displays with a preempting objective therefore may benefit from appearing before the shopping zone with its full display of all alternatives, because they can trigger an immediate reaction by shoppers without entailing further comparison with other alternatives. The effectiveness of first screen displays in attracting attention and influencing purchase decisions may be reinforced by their direct purchase opportunity, greater visibility and exclusivity advantages (see Appendix A). In contrast with aisle and shelf tag displays, first screen displays are larger, appear at mid-screen positions, provide a direct buy button, and face little or no competition with simultaneously displayed ads or products, which should enhance their ability to attract attention and elicit a direct response. Comparing shelf tag with aisle displays, shelf tag displays have the advantage of being situated in the center of the shopping zone but have the disadvantage of being smaller in size and plagued by more advertising clutter (i.e., simultaneously displayed shelf tags). Previous research indicates that advertising clutter substantially reduces the effectiveness of displays, especially when a high degree of similarity marks the simultaneously displayed ads (e.g., product type, advertising claims) (Anderson and Simester 2001; Cho and Cheon 2004; Keller 1991).

In line with these considerations, we expect first screen displays to have the strongest and shelf tag displays the weakest effect on purchase behavior of hedonic shoppers. Aisle displays take an intermediate position, with visibility and exclusivity advantages over shelf tags but preemption disadvantage compared with first screen displays. Overall, we expect the effect of all display types to be small or insignificant for utilitarian shoppers but expect important differences between display types for hedonic shoppers. Because recent evidence indicates that both types of shoppers visit online grocery stores, we propose: 
Proposition 2: First screen displays have a greater positive effect on the sales of the displayed product than do aisle and shelf tag displays.

Proposition 3: Aisle displays have a greater positive effect on the sales of the displayed product than do shelf tag displays.

\section{DATA AND MODELS}

Data

We obtained market share and category sales data from a major European online grocery store for 120 weeks and across ten different categories. When an online order gets placed, professional shoppers (pickers) fill the order from an independent warehouse; the retailer then delivers the order to the place and at the time specified by the consumer. The online assortment is comparable to that of B\&M stores in the same service area and comprises both food and nonfood categories. For the same store, categories, and time period, we obtain detailed information about online ISD and promotional actions. The first screen, aisle, and shelf tag displays are renewed on the first of each month. In Table 1, we provide an overview of the different displays for the ten FMCG categories, which reveals substantial variation in the display types, category penetration, and purchase frequency (as captured by the category's position based on sales).

$$
<\text { insert Table } 1>
$$

\section{Brand Sales Model}

We use an indirect approach to model effects of ISD on brand sales, in which we specify the sales of brand $\mathrm{b}$ at time $\mathrm{t}\left(\right.$ Sales $\left._{b, t}\right)$ as the product of category sales in $\mathrm{t}$ ( CatSales $_{t}$ ) and the market share of brand $\mathrm{b}$ at time $\mathrm{t}\left(m s_{b, t}\right)$ (e.g., Hanssens, Parsons, and Schultz 2001; Leeflang et al. 2000):

$$
\text { Sales }_{b, t}=\text { CatSales }_{t} \times m s_{b, t} .
$$


This indirect approach can distinguish between (i) category expansion effects, such as when customers who did not plan to buy a product do so in reaction to ISD (captured by CatSales $_{t}$ ), and (ii) brand switching effects, such as when customers who planned to purchase in the category buy a different brand in reaction to ISD (captured by $m s_{b, t}$ ). For in-store marketing instruments such as ISD that mainly attract attention but do not provide a real value advantage, category expansion effects should be weak or insignificant (Bell, Chiang, and Padmanabhan 1999). Categories marked by impulse purchases (e.g., candy) may constitute an exception, but such categories are not included in our data set. By distinguishing between category expansion and brand switching effects, we filter out the effect of ISD on unplanned purchases and investigate differences in effects across display types for customers who planned to purchase the category. We offer an overview of the symbols and model variables in Table 2.

$<$ insert Table $2>$

\section{Market Share Model}

To examine the effect of ISD on brand market share, we estimate an attraction-based market share model. In our empirical setting, as in most other (online) grocery stores, some display types are defined at the brand level (aisle display), whereas others involve the SKU level (first screen and shelf tag displays). Therefore, we use a two-stage hierarchical market share model that can include different predictor variables, defined at the brand and SKU level. Specifically, we use the extended nested multinomial logit (ENMNL) model proposed by Foekens, Leeflang, and Wittink (1997). For reasons of parsimony and in view of the limited number of observations per display type and SKU, we do not include cross-competitive effects of ISD (i.e., extended rather than fully extended NMNL model; Foekens et al. 1997).

Because the traditional attraction model is nested in the hierarchical one, we can also formally test for violations of the independence of irrelevant alternatives assumption in the 
competition patterns between SKUs of different brands (Foekens et al. 1997). In line with the layout of the Web site and the marketing mix strategy, we apply a brand-SKU hierarchy to estimate the effects of different display types at the appropriate level: brand level for aisle displays but SKU level for the other two display types. Our robustness checks, discussed in more detail subsequently, support this hierarchy. Therefore, we define the market share of SKU s $(1, \ldots, \mathrm{S})$ of brand $\mathrm{b}(1, \ldots, \mathrm{B})$ at time $\mathrm{t}\left(m s_{s b, t}\right)$ as:

$$
m s_{s b, t}=m s_{b, t} \times m s_{s \mid b, t}
$$

where $m_{b, t}$ is the market share of brand $\mathrm{b}$ at time $\mathrm{t}$, and $m_{s \mid b, t}$ is the market share of SKU $\mathrm{s}$ within brand $b$ at time $t$. The market share of the lower (SKU) level in our nested model can be formalized as:

$$
m_{s \mid b, t}=\frac{A_{s \mid b, t}}{\sum_{i=1}^{S} A_{i \mid b, t}}
$$

where

$$
A_{s \mid b, t}=\exp \left[\alpha_{s}+\sum_{m_{l}=1}^{M_{l}} \beta_{m_{l}} X_{m_{l}, s b t}\right]
$$

In addition to a SKU-specific intercept $\left(\alpha_{s}\right)$, we include marketing mix effects $\left(X_{m, s b, t}\right)$

measured at the SKU level, such that $\beta_{m_{l}}$ is a parameter that captures the effect of the marketing mix variable $\mathrm{m}_{1}\left(1, \ldots, \mathrm{M}_{1}\right)$ on the (conditional) market share and the subscript 1 indicates the lower level effect.

We include a first screen display variable and promotion-specific shelf tag variables. Because the latter are used exclusively as promotion signals, shelf tag effectiveness may depend on the type of promotion announced. For this reason, we include promotion-specific shelf tag variables in our model. From our data set, we identify four promotional activities: price cuts, loyalty points, free offers, and premium promotions. Not all promotional shelf tag 
variables get incorporated into each model specification, because some categories only used a subset during our observation period. Furthermore, we do not include price variables, because product prices remained largely the same during the study period (e.g., in the butter category, the regular prices of 10 of 22 SKUs [45.5\%] were the same throughout the observation period, and the regular prices of the remaining 12 SKUs changed at approximately the same moment; $\mu_{\text {price }}=7.08$ with s.e. $=.22$ ). Thus, the effect of the price variables could not be distinguished from the SKU-specific intercepts.

The market share of the higher (brand) level in our nested model can be written as:

$$
m_{b, t}=\frac{A_{b, t}}{\sum_{j=1}^{B} A_{j, t}}
$$

where:

$$
A_{b, t}=\exp \left[\alpha_{b}+\sum_{m_{u}=1}^{M_{u}} \beta_{m_{u}} Y_{m_{u} b, t}+(1-\sigma) I V_{b, t}\right]
$$

We again include the brand-specific intercept $\left(\alpha_{b}\right)$ and add the marketing mix variables of brand $\mathrm{b}$, defined at the brand level $\left(Y_{m_{u} b, t}\right)$, where $\beta_{m_{u}}$ is a parameter that reflects the effect of marketing mix variable $\mathrm{m}_{\mathrm{u}}\left(1, \ldots, \mathrm{M}_{\mathrm{u}}\right)$ on brand market share and the subscript $\mathrm{u}$ stands for the higher (upper) level effect.

Because aisle displays are defined at the brand level, we include an aisle display variable in Equation 6 but not in Equation 4. In addition, although the first screen display offers a direct purchase opportunity to buy the featured SKU and for that reason especially affects the purchase probability of this SKU (lower level, Equation 4), we also include a first screen display variable at the brand level (higher level, Equation 6) to capture additional attention-steering effects for the brand as a whole. Doing so allows us to capture potential spillover or 'halo' effects that may result from featuring one SKU to the brand as a whole, 
above and beyond the increase that comes from the heightened SKU attractiveness and which is incorporated through the inclusive value (see below). When customers do not immediately react to the first screen display by clicking on the buy button, seeing one of the brand's SKUs on the shelf later on may trigger a recognition or even a 'good deal' reaction, and in this way increase the attractiveness of non-featured SKUs of the same brand. Shelf tag displays are less likely to generate additional effects at the brand level beyond SKU-specific effects since they are shown at the low-level SKU list page only, and on that page, attempt to highlight the featured SKU and reduce competition from other SKUs on the shelf. Therefore, they only appear at the lower level (Equation 4), not at the higher level (Equation 6), of the market share model. The robustness checks, explained in more detail later, confirm our model choices.

The effect of changes in SKU attractiveness on overall brand attractiveness is captured by the inclusive value for brand $b$, defined as:

$$
I V_{b, t}=\log \left(\sum_{s=1}^{S} \exp \left[\alpha_{s}+\sum_{m_{l}=1}^{M_{l}} \beta_{m_{l}} X_{m_{l} s b, t}\right]\right)
$$

The inclusive value variable is the log of the sum of the attractions of all SKUs belonging to brand $\mathrm{b}$. The inclusive value increases when an SKU belonging to brand $\mathrm{b}$ becomes more attractive as the result of a display (significant positive effect of $\beta_{m_{l}}$ resulting from a change in $\left.X_{m_{l} s b, t}\right)$. The term $(1-\sigma)$ indicates the impact of the total attractiveness of the set of SKUs of brand b on the brand's market share, varies between 0 and 1 (Foekens et al. 1997), and determines to what extent an increase in SKU attractiveness (generated by a display) translates into an increase in overall brand attractiveness.

\section{Category Sales Model}

As we indicated previously, we do not expect ISD to have substantial category expansion effects. Yet to be complete and capture overall brand sales effects fully, we 
estimate a multiplicative category sales model $\left(\right.$ CatSales $\left._{t} ; \mathrm{t}=1, \ldots, \mathrm{T}\right)$ that takes the

following form:

$$
\text { CatSales }_{t}=e^{\alpha_{c}} \prod_{m=1}^{M} e^{\delta_{m} X_{m, t}} \text { CatSales }{ }_{t-1}^{\delta_{\text {lagCS }}} \prod_{h=1}^{H} e^{\chi_{h} D_{h t}},
$$

where $D_{h t}$ are seasonal dummies, $h(1, \ldots, \mathrm{H})$ is an index for holiday and special event periods (summer, Easter, Christmas/New Year, and midterm), CatSales ${ }_{t-1}$ is a lagged effect of sales to capture carryover effects, and $X_{m, t}$ captures the effects of marketing mix variables at the category level (first screen, aisle, and up to four promotion-specific shelf tag display variables, if relevant). $\alpha_{c}, \delta_{m}, \delta_{\text {lagCS }}, \chi_{h}$ are parameters to be estimated.

\section{RESULTS}

\section{Estimation Results of Market Share Model}

To estimate the hierarchical market share model, we use a sequential estimation procedure: After estimating the parameters from Equation 4, we calculate the inclusive value $I V_{b, t}$ from Equation 7 and estimate the parameters from Equation 6, given the values of $I V_{b, t}$ (Foekens et al. 1997). We provide the estimation results in Table 3. For the lower (SKU) level model (Panel B), we report the number of insignificant, positive, and negative coefficients ( $\alpha$ $=.05)$. For the higher (brand) level model (Panel A), we report the parameter estimates with their significance levels. We also include, for both levels of the hierarchical market share model, the Stouffer combined test, ${ }^{2}$ which provides an overall test of the parameters (Rosenthal 1991; Wolf 1986). The combined test can produce statistical generalizations with

\footnotetext{
${ }^{2}$ The Stouffer test, or method of adding Zs (standard normal values), starts by finding corresponding Zs for onetailed $p$-levels for each of the estimations or categories. When effects are in the same (expected) direction, the corresponding Zs have the same sign; the signs differ if the results are in the opposite direction. The Zs then are summed and divided by the square root of the number of tests combined (i.e., number of estimations or categories). This new $\mathrm{Z}$ follows a standard normal distribution and corresponds to the $p$-value that the combined results could have occurred under the corresponding null hypothesis (Gijsbrechts, Campo, and Goossens 2003). In addition to the Stouffer test, we compute a Winer combined test, which produces the same results.
} 
respect to the combined evidence resulting from all the estimations and categories (Wolf 1986). In addition, we enhance the combined tests with an effect size index for each variable that offers insights into the strength of the relationship, i.e., the degree to which the phenomenon occurs in the population (Wolf 1986). We first convert the t-value for each variable to an effect size index $d$ and take the average of effect sizes $\left(d_{a}\right)$ to represent the mean effect size across all estimations and categories (Wolf 1986). As a robustness check, we rerun the tests with the Pearson product moment correlation $r$ as a common metric and find the same results. Cohen (1977) provides the following guidelines for the effect size: small when d $=.2$, medium when $\mathrm{d}=.5$, and large when $\mathrm{d}=.8$. Overall, Table 3 shows that for most categories there is a reasonable-good fit (based on the residual sum of squares and corrected total) for the lower level of the market share models, and a good fit for the higher level of the market share models.

$<$ insert Table $3>$

For first screen displays, we find very strong, positive effects at the lower level of the hierarchical market share model (Panel B, Table 3): In 12 of 18 lower-level estimations in which a first screen display is present, the effect is positive and significant, and in none of the cases do we find a significant negative effect. For all categories, at least one of the lower-level models produces a significant and positive effect for the first screen display variable. The Stouffer combined test indicates that the null hypothesis of no significant first screen display effect common to each of the estimations should be rejected $(\mathrm{p}<.01)$, and the mean effect size (.58) points to a medium effect. The results at the higher level of the hierarchical model (Panel A, Table 3) demonstrate that these SKU-level effects lead to a significant increase in the brand's market share in each of the examined product categories. The parameter of the inclusive value is significant for all categories (mineral water at .10; all other categories at .01 ) with values within the 0 and 1 range (we report $1-\sigma$; Stouffer test $p<.01$, and large 
effect size $=1.12$. In addition, for several categories (beer and toilet paper at $1 \%$, drinking yoghurt at 10\%), the general (non-SKU-specific) first screen display variable included at the higher level of the market share model also has a significant positive effect on the market share of the brand (Panel A, Table 3: Stouffer $p<.01$; yet with a small mean effect size across categories of .23 and high standard deviation of .48, indicating that there is substantial variation in effectiveness across categories). Overall, these results indicate that first screen displays substantially improve brand market share for each of the examined product categories. The small number of higher-level brand-specific effects suggests that there are limited or no spillover effects of SKU-based first screen displays on the brand as a whole. Yet, because of the significant inclusive value effect, first screen displays affect the brand's position through the increased attractiveness of the featured SKU which makes the brand more attractive compared to competing brands and in this way steals sales from these competing brands. In addition, the differences between the lower-level, SKU-specific effects show that the effectiveness of first screen displays may strongly depend on the attractiveness of the featured SKU.

An aisle display, in contrast, does not appear to improve brand market share in all categories. We find a significant, positive effect in only four of the ten categories (mineral water, cola, drinking yoghurt, margarine) at the higher level of the hierarchical market share model (Panel A, Table 3). This finding also is reflected in the results of the Stouffer test, which indicate that aisle displays produce a positive, significant effect on brand market share $(p<.01)$ but with a small mean effect size $(.20)$ and rather large standard deviation (.33).

Finally, as expected, the effect of shelf tag displays on the lower level of the hierarchical market share model differs substantially depending on the type of promotion (Panel B, Table 3). We find no effects for price cuts or free promotions (Stouffer test $p>.10$ ), but loyalty points and premium promotions have significant effects on the market share of an 
SKU of a specific brand (Stouffer test $p<.01$ ). Yet, the number of significant coefficients across estimations remains small, which is reflected in the small mean effect sizes and relatively large standard deviations of the Stouffer test $(.14$, s.e. $=.25$ for loyalty points; .10 , s.e. $=.27$ for premium promotions).

To obtain a better insight into the magnitude of the overall brand market share effects of different display types, we derive the percentage change in brand market share generated by a display via quasi-elasticities (see Appendix B). Since shelf tags have a very limited effect on brand market share, we focus on the other two display types. Figures 1 and 2 provide a visual representation of the display effects based on the formulae in Appendix B. Figure 1 depicts the percentage change in brand market share caused by a display, as a function of the brand's initial market share ( $\left.m_{b, t}\right)$ which is varied from .01 to 1. Using Equation (B.1) in Appendix B, we display the percentage change in brand market share generated by a first screen display in Figure 1a. The parameter values used to derive the functions are displayed below Figure 1. We use the lowest and highest values of the estimated response parameters ( $\beta_{F S, l}$ and $\left.\beta_{F S, u}\right)$, and fix the value of the featured SKU's initial market share $\left(m s_{s b, t}\right)$ and the inclusive value coefficient $(\sigma)$ at .5. In the same way and using the lowest and highest values of the estimated aisle display response parameters $\left(\beta_{\text {Aisle } u}\right)$, Equation (B.2) in Appendix B leads to the function displayed in Figure $1 \mathrm{~b}$ and captures the percentage change in brand market share generated by an aisle display. Figure 2 presents the percentage change in brand market share caused by a first screen display as a function of the featured SKU's initial market share $\left(m s_{s b, t}\right)$ which is varied from .01 to 1. We again use Equation (B.1), the lowest and highest values of the estimated response parameters $\left(\beta_{F S, l}\right.$ and $\left.\beta_{F S, u}\right)$ and fixed values for the initial brand market share $\left(m s_{b, t}\right)$ and inclusive value coefficient $(\sigma)$ equal to .5 , to derive the graphs. 
$<$ insert Figure 1 and 2>

A comparison of the graphs in Figure 1 clearly confirms that first screen displays (Figure 1a) are more effective than aisle displays (Figure 1b) over the whole range of the initial brand market share. The difference in effectiveness is largest for brands with a relatively low initial market share and declines but remains substantial for higher levels of the initial brand market share. The results in Figure 2 demonstrate that the effectiveness of first screen displays depends on the attractiveness of the featured SKU. First screen displays for highly attractive SKUs (large initial market share) generate a much stronger increase in the brand's market share than do those for less attractive SKUs.

We also run simulations based on the actual marketing environment to obtain estimates of brand market share increases realized by the display actions in our data set. For each observed display action, we computed (i) the forecasted brand market share with the display and (ii) the forecasted brand market share that would have been obtained without a display. The ratio of (i) to (ii) provides an indication of the actual display effect. In line with Figure 1, the simulation results indicate that, on average, the percentage increase in brand market share caused by a first screen display (average $=16.65 \%, \max =106.3 \%, \min =.68 \%$ ) is substantially larger than that caused by an aisle display (average $=5.95 \%$, $\max =33.7 \%$, $\min =.44 \%$ ). As an illustration for the link between the figures and the simulation, we focus on the minimum increase in brand market share resulting from an aisle display (.68\%), which was observed for a brand (coca cola) with a very high initial market share (around 95\%), and a rather low responsiveness parameter for the aisle display (Table 3). Looking at Figure 1b, the percentage increase is indeed low and around .68\% as we found in our simulations. Estimation Results of Category Sales Model 
For the category sales model, we report the parameter estimates and their significance level, the Stouffer test, and the mean effect size in Table 4. Overall, Table 4 shows that the model fit is acceptable, especially for the more frequently purchased product categories.

$$
<\text { insert Table } 4>
$$

For almost all categories, we observe a positive significant effect of the lagged sales variable and negative significant effects for the seasonal dummy variables. As expected, we find no or very small effects of ISD on category sales: there are no significant positive effects of first screen displays, aisle displays have significant positive effects for four categories only, and the majority of shelf tag displays are not significant. The only significant effects emerge for loyalty points, which again can be attributed to the effect of the specific promotion type rather than a shelf tag display effect.

\section{Effects of ISD on Brand Sales}

Because of the weak or insignificant effects at the category sales level, the overall effects of ISD on brand sales mainly depend on the market share effects (Equation 1). We find strong evidence in support of Proposition 1's claim that online ISD have a positive effect on brand sales. The results also provide support for Proposition 2. First screen displays clearly outperform aisle and shelf tag displays. To take the positive effects of the aisle display variable on category sales into account, we rerun the simulations on the overall brand sales level. The results are very similar to those obtained for the brand market share model. The average increase in brand sales caused by first screen displays is larger than the average increase in brand sales caused by aisle displays. First screen displays also have a stronger effect on brand sales than do shelf tag displays. In support of Proposition 3, aisle displays outperform shelf tag displays in the majority of cases. Shelf tag effects appear significant for a limited number of cases and promotion types only. The effect appears to depend predominantly on the type of promotion rather than the presence of a tag announcing one. 


\section{Robustness Checks}

To verify the validity of our findings, we conduct several robustness checks for the category sales and market share models. In the category sales model, we estimate several alternative model specifications, but none of them result in significantly better estimation results. We also test for first-order autocorrelation using the Durbin-Watson test. For the market share model, we estimate alternative specifications of the hierarchical attraction model, replacing the brand-SKU hierarchy with a size-SKU or flavor-SKU hierarchy. In addition, instead of estimating a general inclusive value effect (Equation 7), we estimate models with nest-specific inclusive value effects. We also rerun the models with an overall instead of promotion-specific shelf tag variable, which captures simply the announcement of a promotion. For none of these checks does the face validity or model fit improve.

For the operationalization of the promotion variables, we use the amount of price reductions and loyalty points for price cut and loyalty point promotions and a dummy variable for the other two promotion types (see Table 2), because previous research has noted that consumers are sensitive to the (monetary) value of a promotion (DelVecchio, Krishnan, and Smith 2007). Robustness checks indicate that using dummy variables for the price cut and loyalty point promotion variables or using a monetary value expression for the free promotion variable reduces model fit. We further verified the choice of including the displays at the different levels of the market share model, by adding shelf tag variables at the higher level of the market share model and SKU-specific aisle display variables at the lower level of the market share model. Although there are few reasons to expect an additional brand-level 'halo' effect for shelf tag variables, a plausible exception could be that a shelf layout by brand stimulates proximity effects in the advantage of non-featured adjacent SKUs of the same brand (Breugelmans et al. 2007). Similarly, there are no reasons to expect important differential effects of aisle displays at the SKU level. Robustness checks indeed reveal the 
nonexistence of shelf tag effects at the higher level, and SKU-specific aisle display effects at the lower level. Finally, adding lagged versions of the promotion-specific shelf tag variables in our model, as a means to capture possible dynamic effects, does not result in estimation improvements. Previous researchers have indicated that dynamic promotion effects are relatively hard to capture (Chan, Narasimhan, and Zhang 2008), and this difficulty may become even more pertinent with the aggregate nature of our data and less stable shopping pattern of online buyers.

\section{CONCLUSIONS AND DIRECTIONS FOR FURTHER RESEARCH}

The objectives of this research were twofold. First, we wanted to examine whether instore displays (ISD), which represent highly effective and frequently used in-store marketing instruments for B\&M stores, can be used effectively to stimulate brand sales in online stores. Second, we wanted to investigate the moderating effect of display characteristics by comparing the effectiveness of three major display types that pursue different objectives and effects. To derive propositions on the effectiveness of ISD in online stores and on the differences in effectiveness across display types, we perform a theoretical analysis of the mechanisms underlying observed display effects and of the possible impact of the virtual store environment. Next, to test these propositions, we estimate a hierarchical brand market share and category sales model that incorporate the effect of three display types that differ in their attention- and competition-related features. We examine the effects for ten different FMCG categories which increases the external validity of our results and provides insight into potential differences in display effects across categories.

\section{Overall Effectiveness of ISD in an Online Shopping Context}

Previous studies in traditional grocery settings demonstrate that ISD can be a very effective instrument to increase brand sales. Our results confirm that ISD also have positive 
effects on brand sales in online grocery stores, generating an increase in brand sales of up to $106 \%$. In contrast with previous claims that online stores attract only convenience-oriented shoppers that are less sensitive to in-store marketing instruments, our findings demonstrate that ISD can influence online buying behavior and that online shoppers may be susceptible to in-store incentives. Online retailers and manufacturers may therefore benefit from introducing incentives and decision cues (e.g., ISD) that draw online shoppers' attention to specific products and thus alter their behavior.

Comparing brand and category level effects, it is clear that the brand switching effect dominates the category sales effect. Online ISD have a significant positive effect in a much larger number of product categories at the brand (market share) level than at the category sales level. In addition, when significant, the magnitude of the category sales effect is in most cases quite limited compared to the boost in brand market share ISD appear to produce. Online retailers and manufacturers should therefore realize that ISD tend to change online shoppers' brand choice rather than their category incidence decision. Previous research has shown that, also in a B\&M setting, in-store merchandising efforts especially affect brand choice decisions, and to a lesser extent primary demand (cf. Bell, Chiang, and Padmanabhan, 1999). Whether the magnitude and composition of the online display effects observed in our

study are comparable to those obtained in B\&M stores is difficult to assess, due to the lack of a clear benchmark (i.e., no meta-analysis of display effects has been published) and uncontrolled differences in the research settings (e.g., store characteristics, examined categories, and brands).

\section{Differences in Effectiveness between In-Store Display Types}

Not all display types are equally effective in increasing brand sales. As we expected, displays that mainly serve a preempting objective outperform those with a targeting objective. The average increase in brand market share for first screen displays is more than twice as 
large as that for aisle displays, and we observe virtually no significant effects for shelf tag displays. The preemption advantage of first screen displays becomes even more pronounced when attractive SKUs are featured on the first page, with a boost in the market share of up to $106 \%$. This leads to two important conclusions for the planning of online display actions. First, the results demonstrate that the advantages of featuring a product first, with no or limited competition from other brands in the category, more than compensates for the possible disadvantages of a less functional position in the traveling zone of the online store. Second, selecting the right items to feature can determine the success of the preemption strategy, in that a much stronger effect results from the display of more attractive SKUs. This implication is consistent with previous findings in advertising literature that indicate that more appealing and familiar products attract customer attention more easily (e.g., Keller 1991).

Aisle displays only have significant effects on brand market share in about half of the examined product categories and, when significant, provide a smaller increase in brand market share than do first screen displays. In line with our expectations however, aisle displays clearly outperform shelf tag displays for enhancing brand sales. Both ISD are located in or near the shopping zone, and thus serve a targeting objective, but the difference in effectiveness stems from the entrance position of aisle displays and the higher degree of advertising clutter for shelf tag displays. Aisle displays appear in somewhat isolated, borderscreen positions preceding the SKU list while shelf tag displays get dispersed all over the online shelf, often in competition with several other shelf tags that make similar promotional claims, which increases the risk for diluted attention effects.

\section{Category Differences in ISD Effects}

We find a high degree of consistency in the results across product categories. In each category, the market share effects of ISD appear to dominate category sales effects. In addition, we find very similar differences in effectiveness across display types, with 
significant and much stronger first screen display effects in each of the examined categories.

The main differences across categories are the somewhat unexpected positive category sales effects of aisle displays in some of them. A closer look at the online grocery store's organization reveals that this differentiation is especially evident when the category pages contain close substitute categories, such that the displays may stimulate cross-category substitution. To test these cross-category effects and determine whether category switching is a reason for the increase in category sales we observe, we need more information about the substitution possibilities and sales level of other categories.

\section{Managerial Implications}

This research has important implications for both manufacturers and retailers, the implementation of ISD depending both on manufacturers' incentives to initiate them and retailers' willingness to implement them (Ailawadi et al. 2009). Manufacturers can use our results to identify the differences between and determinants of successful display types when planning their in-store marketing mix actions. The advantages of preempting competition by appearing early in the shopping process dominate the possible advantages of targeting buyers at the time and place they make their choices. In deciding which display to use, manufacturers should take the risk of advertising clutter into account and strive to gain more isolated, exclusive display positions. For retailers, these results provide useful guidelines for determining the cost structure of the display fees and managing their display space allocations when collaborating with manufacturers. In addition, though retailers may be tempted to increase the number of shelf tag displays available in the same space, the resulting decrease in effectiveness could backfire, in the form of manufacturers' reduced willingness to pay for the display. Moreover, because of the dominance of brand switching over category sales effects, retailers should be aware that they can benefit most by charging the individual brand for the opportunity to steal share or by pushing one of their own private label brands to do so, as ISD 
tend to have a weak effect on category sales. In addition, it may be interesting to explore possible cross-category substitution effects, especially for those categories that are positioned in the neighborhood of close substitute categories on the website.

\section{Limitations and Avenues for Further Research}

Although our study provides interesting new insights into the effectiveness of ISD in an online grocery shopping context and the differences in effectiveness across display types, it also has important limitations and points to several interesting areas for additional research. A first limitation concerns the aggregate level of analysis and lack of information about individual-level differences in display reactions. Further research should shed more light on these issues by, for example, estimating purchase incidence, purchase quantity, and brand choice models at the individual level. An analysis of individual differences in display responses also might provide useful guidelines for online retailers and help them assess customization opportunities (Zhang and Krishnamurthi 2004). In addition, to clarify the black box that remains between display incentives and behavioral reactions, researchers could obtain insight into intermediate outcomes by measuring self-regulation and related consumer characteristics explicitly through a survey or experimental analysis, or by using eye-tracking or clickstream data to examine individual attention to ISD.

Second, the validity of our findings receives support from the consistency across ten FMCG categories, yet an analysis of a more extensive set of categories that differ on other important characteristics should test for and explain potential differences in display effectiveness across categories. Our data set comprises food and nonfood items and categories that differ in purchase frequency, but it mainly concentrates on staple products (i.e., no impulse products, specialties, or perishables). The results at the category sales level further indicate that an analysis of cross-category effects could provide useful additional insights and a more complete view of online display effects, because it would allow to explicitly 
investigate the impact of ISD on the category sales of related, substitute, or complementary categories. Similarly, replicating the study in another online retail setting would be an interesting area for further research.

Third, to obtain a more accurate assessment of online display effects and derive better guidelines to support decisions on ISD, the model and analysis could be extended to incorporate dynamic effects and interaction effects between display types. These model extensions might provide useful additional insights and guidelines to support display frequency, timing, and display mix decisions.

Fourth, the results regarding the brand sales effects of online ISD should be integrated with information on display costs to assess their profitability. Such analyses in an online context may provide useful additional insights that would help retailers and manufacturers to improve their in-store marketing plans. Online ISD costs may differ substantially from offline display costs, due to the higher flexibility in a virtual store environment; an online store experiences minimal costs to change or replace ISD and no costs for creating physical displays. An investigation of the profitability and specific advantages of online ISD also would offer interesting insights into customization opportunities of online ISD (Zhang and Wedel 2009). Because our results confirm that not all display types are equally effective, manufacturers need to trade off differences in costs and effectiveness across the display types. Additional research could provide useful insights to support these decisions by examining profitability differences across display types and relating them to product characteristics, such as the number of available brands or SKUs per brand and the attractiveness of flagship SKUs. 
Table 1: Category Overview and Descriptors of ISD

\begin{tabular}{|c|c|c|c|c|c|c|c|c|c|}
\hline \multirow{2}{*}{ Category } & \multirow{2}{*}{$\begin{array}{c}\text { Position } \\
\text { based on } \\
\text { Sales }\end{array}$} & \multirow{2}{*}{$\begin{array}{l}\text { Number } \\
\text { of Brands } \\
\text { in the } \\
\text { Category }\end{array}$} & \multirow{2}{*}{$\begin{array}{l}\text { Number } \\
\text { of SKUs } \\
\text { in the } \\
\text { Category }\end{array}$} & \multirow{2}{*}{$\begin{array}{c}\text { First } \\
\text { Screen } \\
\text { Display }^{* *}\end{array}$} & \multirow{2}{*}{$\begin{array}{c}\text { Aisle } \\
\text { Display }^{* * *}\end{array}$} & \multirow[b]{2}{*}{ Price Cuts ${ }^{* *}$} & \multicolumn{2}{|c|}{ Shelf Tag Display } & \multirow[b]{2}{*}{ Premium $_{\text {Promotions }}^{* *}$} \\
\hline & & & & & & & $\begin{array}{l}\text { Loyalty } \\
\text { Points** }\end{array}$ & $\begin{array}{c}\text { Free } \\
\text { Promotions }\end{array}$ & \\
\hline Cola & 3 & 3 & 27 & $34.6 \%(6)$ & $19.2 \%(2)$ & $38.5 \%(10)$ & $3.8 \%(2)$ & $53.5 \%(6)$ & $50.8 \%(10)$ \\
\hline Sparkling water & 8 & 8 & 23 & $11.5 \%(2)$ & $11.5 \%(3)$ & $42.3 \%(10)$ & $3.8 \%(1)$ & $74.2 \%(11)$ & $21.7 \%(4)$ \\
\hline Beer & 9 & 3 & 18 & $19.2 \%(4)$ & $19.2 \%(3)$ & $46.2 \%(11)$ & $7.7 \%(2)$ & $93.3 \%(11)$ & $36.7 \%(7)$ \\
\hline Toilet paper & 10 & 3 & 17 & $53.8 \%(7)$ & $7.7 \%(2)$ & $50.0 \%(11)$ & $11.5 \%(4)$ & $66.7 \%(8)$ & n.r. \\
\hline Shower soap & 37 & 9 & 49 & $23.0 \%(4)$ & $11.5 \%(3)$ & $30.8 \%(7)$ & $11.5 \%(4)$ & $86.7 \%(10)$ & n.r. \\
\hline Margarine & 43 & 13 & 36 & $15.4 \%(2)$ & $7.7 \%(2)$ & $38.5 \%(9)$ & $11.5 \%(3)$ & n.r. & n.r. \\
\hline Butter & 45 & 6 & 22 & $15.4 \%(3)$ & $7.7 \%(2)$ & $23.0 \%(4)$ & $11.5 \%(2)$ & n.r. & $10.8 \%(2)$ \\
\hline
\end{tabular}

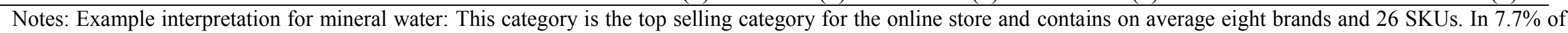
the observation period, at least one SKU was promoted by a first screen display; only one SKU received such a display. Aisle displays were present during $23 \%$ of the

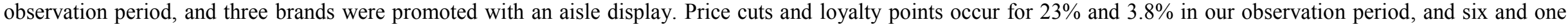

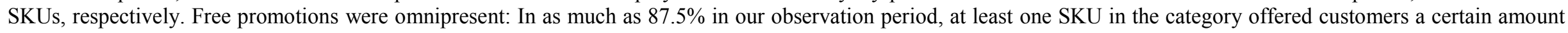
for free. Premium promotions occurred $30 \%$ of the time and for three SKUs. n.r. = not relevant (the category did not use the promotion type during our observation period).

${ }^{*}$ SKU (stockkeeping unit) represents a specific product type, flavor, and/or package size of a given brand.

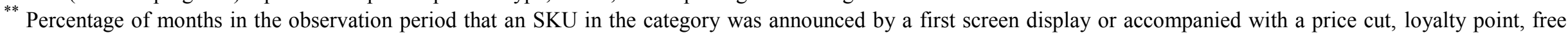
offer, or premium promotion (number of SKUs promoted with a first screen, price cut, loyalty point, free or premium promotion display).

${ }^{* * *}$ Percentage of months in the observation period that an aisle display promoted all SKUs of a brand in the category (number of brands promoted with an aisle display). 
Table 2: Variables in the Market Share and Category Sales Models Brand Sales

$$
\text { Sales }_{b, t}=\text { CatSales, } \times m s_{b, t}
$$

\section{Brand Market Share}

$m s_{s b, t}=m s_{b, t} \times m s_{s \mid b, t}$

with $m_{b, t}=$ market share of brand $\mathrm{b}$ at time $\mathrm{t}$, and $m_{s \mid b, t}=$ market share of SKU s within brand $\mathrm{b}$ at time $\mathrm{t}$

\section{Market share of the higher (brand) level}

$$
\begin{aligned}
& m_{b, t}=\frac{A_{b, t}}{\sum_{j=1}^{B} A_{j, t}}, \text { where } \\
& A_{b, t}=\exp \left[\alpha_{b}+\sum_{m_{u}=1}^{M_{u}} \beta_{m_{u}} Y_{m_{u} b, t}+(1-\sigma) I V_{b, t}\right]
\end{aligned}
$$

Link with lower level

$$
I V_{b, t}=\log \left(\sum_{s=1}^{S} \exp \left[\alpha_{s}+\sum_{m_{l}=1}^{M_{l}} \beta_{m_{l}} X_{m_{l} s b, t}\right]\right)
$$

Inclusive value for brand $b$ at time $t$ (based on the parameters of the lower level market share model)

\section{Variables $\left(Y_{m_{u} b, t}\right)$ :}

Aisle $_{b, t}=\overline{\text { Dummy }}$ variable equal to 1 if there is an aisle display for brand $\mathrm{b}$ at time $\mathrm{t}$

$F S_{b, t}=$ Dummy variable equal to 1 if there is a first screen display for brand $b$ at time $t$

\section{Market share of lower (SKU) level}

$$
\begin{aligned}
& m_{s \mid b, t}=\frac{A_{s \mid b, t}}{\sum_{i=1}^{S} A_{i \mid b, t}}, \text { where } \\
& A_{s \mid b, t}=\exp \left[\alpha_{s}+\sum_{m_{l}=1}^{M_{l}} \beta_{m_{l}} X_{m_{l}, s b t}\right]
\end{aligned}
$$

$\underline{\text { Variables }}\left(X_{m_{s} s, t}\right)$ :

$F S_{s b, t}=$ Dummy variable equal to 1 if SKU s of brand $\mathrm{b}$ is announced on the first screen at time $\mathrm{t}$

$P C_{s b, t}=$ The amount of price reduction for SKU s of brand $\mathrm{b}$ at time $\mathrm{t}$

$L P_{s b, t}=$ The number of loyalty points for SKU s of

brand $\mathrm{b}$ at time $\mathrm{t}$

$F P_{s b, t}=$ Dummy variable equal to 1 if SKU s of brand

$\mathrm{b}$ receives a promotion in the form of 'buy $\mathrm{x}$, get $\mathrm{y}$ for free' at time $\mathrm{t}$

$P P_{s b, t}=$ Dummy variable equal to 1 if SKU s of brand $\mathrm{b}$ receives a gift at time $\mathrm{t}$

$$
\begin{gathered}
\text { Category Sales } \\
\begin{aligned}
\text { CatSales }_{t}=e^{\alpha_{c}} & \prod_{m=1}^{M} e^{\delta_{m} X_{m, t}} \text { CatSales }_{t-1}^{\delta_{\operatorname{lag} c S}} \prod_{h=1}^{H} e^{\chi_{h} D_{h t}} \\
\text { with CatSale }_{t}= & \text { Weekly category sales (expressed } \\
& \text { in } €), \mathrm{t}=1, \ldots, \mathrm{T}
\end{aligned}
\end{gathered}
$$

CatSales $_{t-1}=$ Lagged category sales

$D_{h t}=$ Seasonal dummies, with $\mathrm{h}=$ index for holiday and special event periods $(1, \ldots, \mathrm{H})$

Variables $\left(\mathrm{X}_{\underline{\mathrm{m}}, \mathrm{t}}\right)$ :

$F S_{t}=$ Dummy variable equal to 1 if there is a first screen in the category at time $\mathrm{t}$

Aisle $_{t}=$ Dummy variable equal to 1 if there is an aisle display in the category at time $\mathrm{t}$

$P C_{t}=$ Total amount of price cuts in the category at time $\mathrm{t}$

$L P_{t}=$ Total number of loyalty points in the category at time $\mathrm{t}$ $F P_{t}=$ Dummy variable equal to 1 if there is a promotion in the form of 'buy $\mathrm{x}$, get $\mathrm{y}$ for free' in the category at time $\mathrm{t}$

$P P_{t}=$ Dummy variable equal to 1 if there is a promotion in the form of a gift in the category at time $\mathrm{t}$ 
Table 3: Estimation Results for the Hierarchical Market Share Model

\begin{tabular}{|c|c|c|c|c|c|c|c|c|c|c|c|}
\hline & & Min. water & Cola & Spar. water & Beer & Toilet pap. & Fabric soft. & Drink yogh & Shower soap & Marg. & "Butter \\
\hline \multicolumn{12}{|c|}{ A: Higher (brand) level of the market share model: Estimated coefficients } \\
\hline & First screen display & .033 & .043 & -.042 & $.162^{* * *}$ & $.338^{* * *}$ & -.498 & $.183^{*}$ & .118 & -.071 & -.012 \\
\hline & & \multicolumn{10}{|c|}{ Stouffer: $Z_{c}=3.159152^{* * * *} ; \mathrm{d}_{\mathrm{a}}=.23$} \\
\hline & Aisle display & $.105^{* * *}$ & $.106^{* *}$ & .090 & -.082 & -.060 & -.131 & $.229^{* * * *}$ & -.002 & $.311^{* *}$ & .053 \\
\hline & & \multicolumn{10}{|c|}{ Stouffer: $Z_{c}=2.804759^{* * * *} ; d_{a}=.20$} \\
\hline & Inclusive value (1-б) & $.106^{*}$ & $.958^{* * * *}$ & $.542^{* * * *}$ & $.464^{* * *}$ & $.103^{* * *}$ & $.758^{* * *}$ & $.659^{* * * *}$ & $.829^{* * *}$ & $.191^{* * *}$ & $.858^{* * *}$ \\
\hline & & \multicolumn{10}{|c|}{ Stouffer: $Z_{c}=14.6267^{* * * *} ; d_{a}=1.12$} \\
\hline Model fit & & .960 & .990 & .935 & .905 & .352 & .545 & .969 & .673 & .832 & .908 \\
\hline
\end{tabular}

\section{B: Lower (SKU) level of the market share model: Number of positive significant, insignificant, and negative significant parameters}

First screen display Positive, significant $(5 \%)$

Not significant

Not significant
significant $(5 \%)$

$\begin{array}{lll}1 & 1 & 1 \\ 0 & 2 & 1 \\ 0 & 0 & 0\end{array}$

Shelf tag display - price cut

Positive, significant (5\%)
Not significant

Negative, significant (5\%)

$\begin{array}{llll}0 & 0 & 1 & 0 \\ 3 & 0 & 3 & 2 \\ 0 & 2 & 0 & 1\end{array}$

$\begin{array}{ccr}0 & 0 & 1 \\ 0 & 0 & 0 \\ \text { Stouffer: } & Z_{c}=11.47828^{* * * *} ; d_{a}=.58\end{array}$

$\begin{array}{ll}1 & 1 \\ 0 & 0 \\ 0 & 0\end{array}$

elf tag display - loyalty point

Positive, significant (5\%)
Not significant

Negative, significant (5\%)

$\begin{array}{llll}0 & 0 & 0 & 0 \\ 1 & 1 & 1 & 2 \\ 0 & 0 & 0 & 0\end{array}$
Shelf tag display - free
Positive, significant $(5 \%)$
Not significant

Negative, significant (5\%)

$\begin{array}{llll}2 & 0 & 0 & 0 \\ 4 & 0 & 3 & 1 \\ 1 & 1 & 1 & 2\end{array}$
Shelf tag display - premium
Positive, significant (5\%)
Not significant

$\begin{array}{lll}0 & 0 & 1 \\ 3 & 2 & 2 \\ 0 & 0 & 0\end{array}$
0
1
0
$\begin{array}{ll}1 & 0 \\ 3 & 1\end{array}$
$81382 ; d_{a}=.03$

$\begin{array}{lll}0 & 0 & \text { n.r. }\end{array}$

1

2

Stouffer: $Z_{c}=3.716902^{* * * *} ; d_{a}=.14$

n.r.

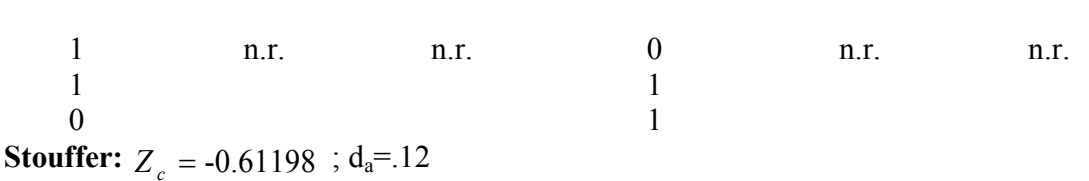

Stouffer: $Z_{c}=-0.61198 ; \mathrm{d}_{\mathrm{a}}=.12$

$\begin{array}{llllll}\text { n.r. } & 0 & \text { n.r. } & \text { n.r. } & \text { n.r. } & 0 \\ & 1 & & & 2 \\ & 0 & & & & 0\end{array}$

Stouffer: $Z_{c}=1.712101^{* *} ; \mathrm{d}_{\mathrm{a}}=.10$ 
Table 4: Estimation Results for the Category Sales Model

\begin{tabular}{|c|c|c|c|c|c|c|c|c|c|c|}
\hline & Min. water & Cola & Spar. water & Beer & Toilet pap. & Fabric soft. & Drink yogh & Shower soap & Marg. & Butter \\
\hline First screen display & -.083 & -.018 & .049 & -.035 & .065 & -.065 & .035 & -.012 & $-.147^{*}$ & .007 \\
\hline & \multicolumn{10}{|c|}{ Stouffer: $Z_{c}=-0.8278 ; \mathrm{d}_{\mathrm{a}}=-.04$} \\
\hline Aisle display & \multicolumn{10}{|c|}{ Stouffer: $Z_{c}=2.827266^{* * * *} ; \mathrm{d}_{\mathrm{a}}=.16$} \\
\hline Shelf tag display - price cut & \multicolumn{10}{|c|}{ Stouffer: $Z_{c}=0.336556 ; \mathrm{d}_{\mathrm{a}}=.01$} \\
\hline Shelf tag display - loyalty point & \multicolumn{10}{|c|}{ Stouffer: $Z_{c}=5,234984^{* * *} ; \mathrm{d}_{\mathrm{a}}=.34$} \\
\hline Shelf tag display - free & -.034 & \multicolumn{8}{|c|}{ Stouffer: $Z_{c}=059959 \& \mathrm{~d}_{\mathrm{a}}=-.18$} & n.r. \\
\hline Shelf tag display - premium & .008 & \multicolumn{7}{|c|}{ Stouffer: $Z_{c}=1,203543 ; \mathrm{d}_{\mathrm{a}}=.10$} & n.r. & $-.327^{* *}$ \\
\hline Lagged category sales & \multicolumn{10}{|c|}{ Stouffer: $Z_{c}=10,09258^{* * * *} ; d_{a}=.56$} \\
\hline Summer & \multicolumn{10}{|c|}{ Stouffer: $Z_{c}=-10.2938^{* * *} ; d_{a}=-.60$} \\
\hline Eastern & $-.126^{*}$ & -.084 & -.088 & $-.196^{* *}$ & $\begin{array}{c}-.150 \\
\text { Stouffer: } Z_{c}=\end{array}$ & $\begin{array}{c}-.207^{* * *} \\
4.73409^{* * * *} ; \mathrm{d}\end{array}$ & $=-.32^{-.265^{* * * *}}$ & $-.183^{* * *}$ & -.060 & -.067 \\
\hline New Year/Christmas & \multicolumn{10}{|c|}{ 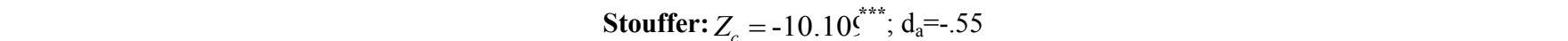 } \\
\hline Mid Term & $-.146^{* *}$ & \multicolumn{8}{|c|}{ Stouffer: $Z_{c}=-4.40800 \varepsilon^{* * *} ; \mathrm{d}_{\mathrm{a}}=-.28$} & -.086 \\
\hline Adjusted R2 & .481 & .297 & .368 & .358 & .464 & .286 & .544 & .143 & .431 & .596 \\
\hline
\end{tabular}


Figure 1: Percentage Changes in Brand Market Share Caused by First Screen and Aisle Displays, with Different Levels of Initial Brand Market Share ${ }^{\mathrm{a}, \mathrm{b}}$

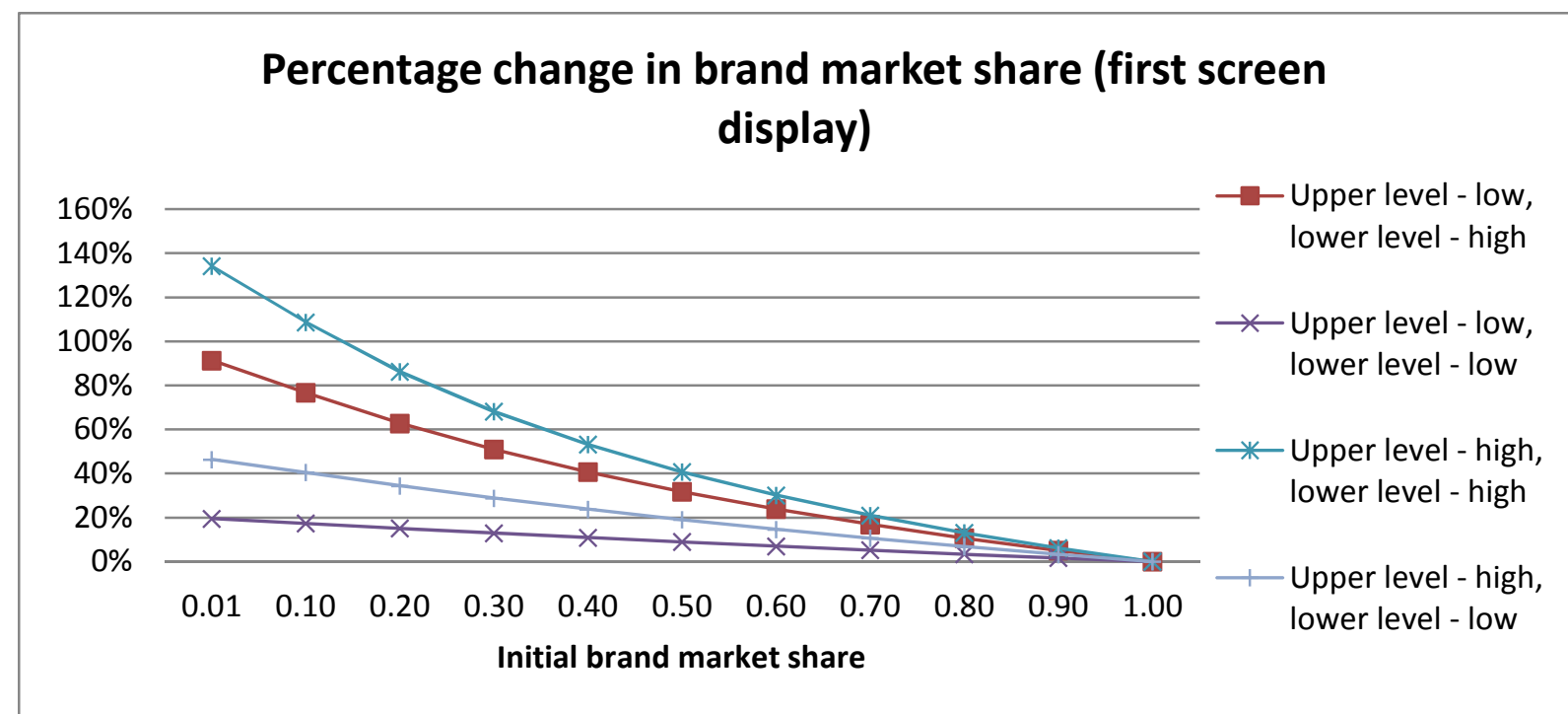

(a) Percentage change in brand market share caused by a first screen display

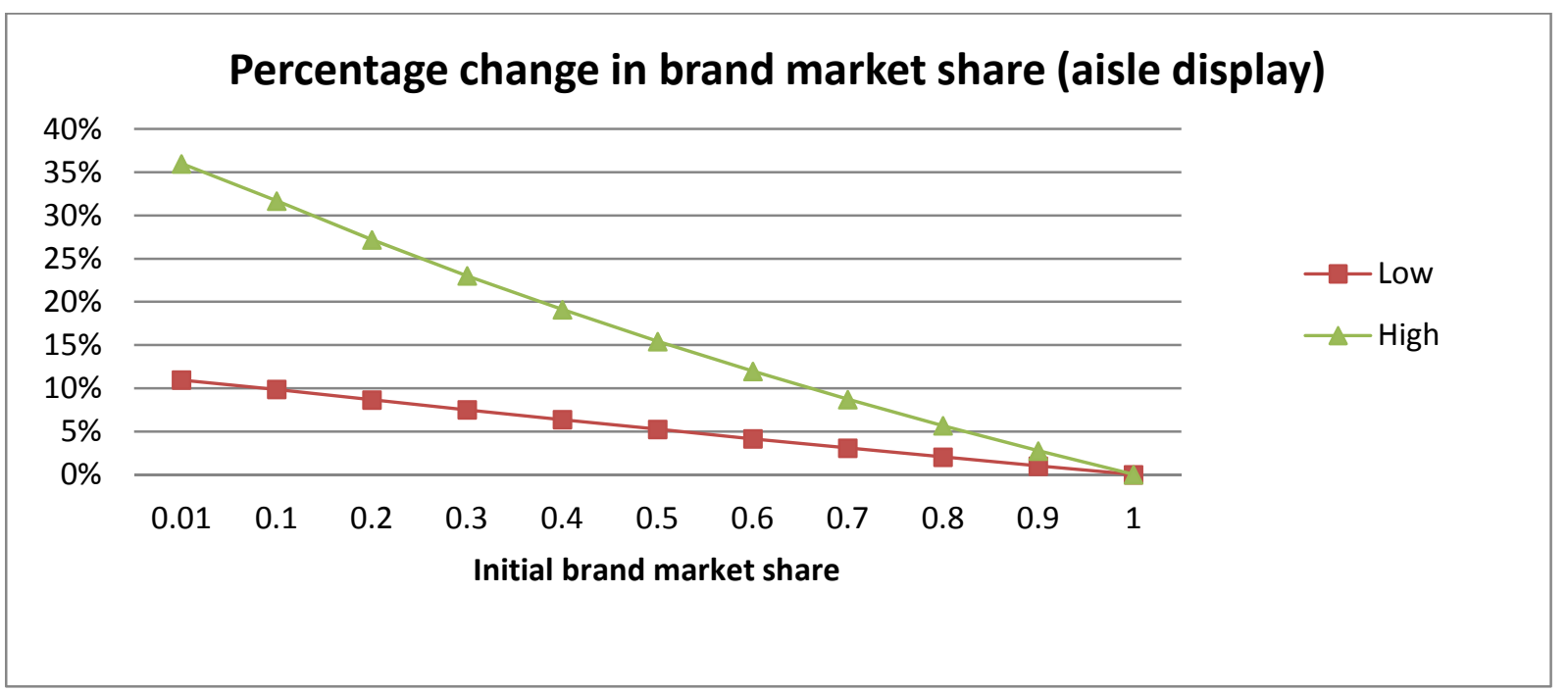

(b) Percentage change in brand market share caused by an aisle display

${ }^{\text {a }}$ Figures based on Equation B.1 (panel a) and Equation B.2 in Appendix B (panel b), using parameters as specified below.

\begin{tabular}{|c|c|c|c|c|c|c|}
\hline & \multicolumn{2}{|c|}{$\begin{array}{c}\text { Initial market share } \\
\text { Brand }\end{array}$} & \multicolumn{2}{c|}{ First screen display } & Incl. & Aisle \\
& Upper & \multicolumn{2}{c|}{ Lower } & value & display \\
\hline & $m s_{b, t}$ & $m s_{s b, t}$ & $\beta_{F S, u}$ & $\beta_{F S, l}$ & $\sigma$ & $\beta_{\text {Aisle } u}$ \\
\hline Figure 1a & & & & & & \\
Upper level low, lower level high & {$[.01,1]$} & .5 & .183 & 1.619 & .5 & n.r. \\
Upper level low, lower level low & {$[.01,1]$} & .5 & .183 & .280 & .5 & n.r. \\
Upper level high, lower level high & {$[.01,1]$} & .5 & .338 & 1.619 & .5 & n.r. \\
Upper level high, lower level low & {$[.01,1]$} & .5 & .338 & .280 & .5 & n.r. \\
\hline Figure 1b & & & & & & \\
Low & {$[.01,1]$} & .5 & n.r. & n.r. & n.r. & .105 \\
High & {$[.01,1]$} & .5 & n.r. & n.r. & n.r. & .311 \\
\hline
\end{tabular}

\footnotetext{
${ }^{\mathrm{b}}$ The actual initial market share of brands that received a display ranges between about $1 \%$ and $95 \%$.
} 
Figure 2: Percentage Changes in Brand Market Share Caused by First Screen Displays, with Different Levels of Featured SKU's Initial Market Share ${ }^{\mathrm{a}, \mathrm{b}}$

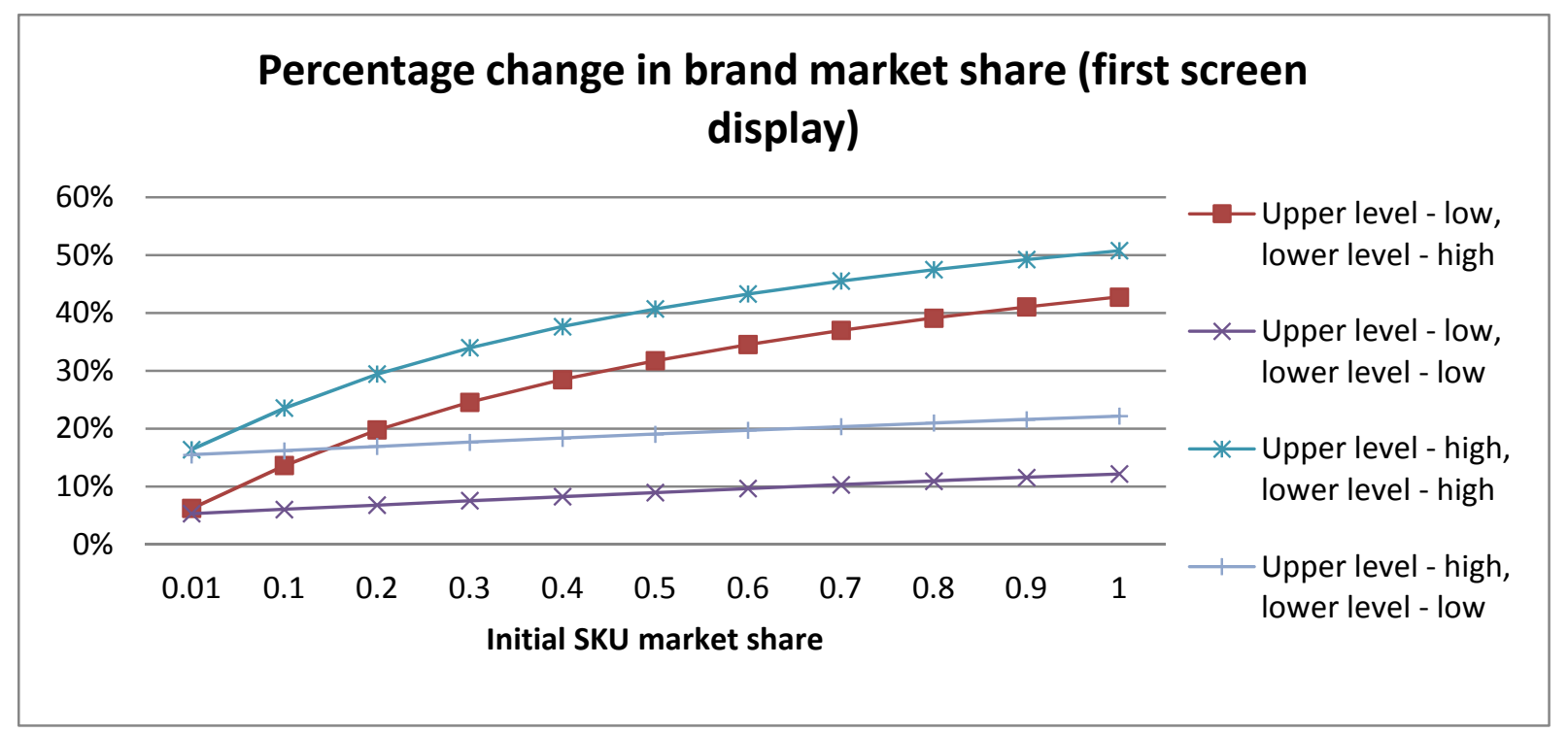

${ }^{\text {a }}$ Figures based on Equation B.1 in Appendix B, using parameters as specified below.

\begin{tabular}{|c|c|c|c|c|c|}
\hline & \multicolumn{2}{|c|}{$\begin{array}{c}\text { Initial market share } \\
\text { Brand }\end{array}$} & \multicolumn{2}{|c|}{$\begin{array}{c}\text { SKU } \\
\text { Lirst screen display } \\
\text { Upper } \\
\text { Lower }\end{array}$} & $\begin{array}{c}\text { Inclusive } \\
\text { value }\end{array}$ \\
\hline & $m s_{b, t}$ & $m s_{s b, t}$ & $\beta_{F S, u}$ & $\beta_{F S, l}$ & $\Sigma$ \\
\hline Upper level low, lower level high & .5 & {$[.01,1]$} & .183 & 1.619 & .5 \\
Upper level low, lower level low & .5 & {$[.01,1]$} & .183 & .280 & .5 \\
Upper level high, lower level high & .5 & {$[.01,1]$} & .338 & 1.619 & .5 \\
Upper level high, lower level low & .5 & {$[.01,1]$} & .338 & .280 & .5 \\
\hline
\end{tabular}

${ }^{\mathrm{b}}$ The actual initial market share of an SKU that received a display ranges between about $10 \%$ and $64 \%$. 
Appendix A: Visual Representation of Different Online Display Types

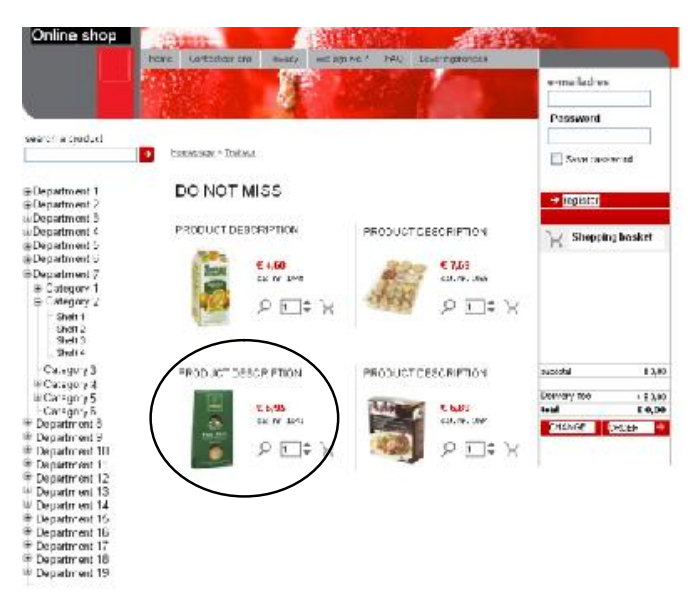

First screen display

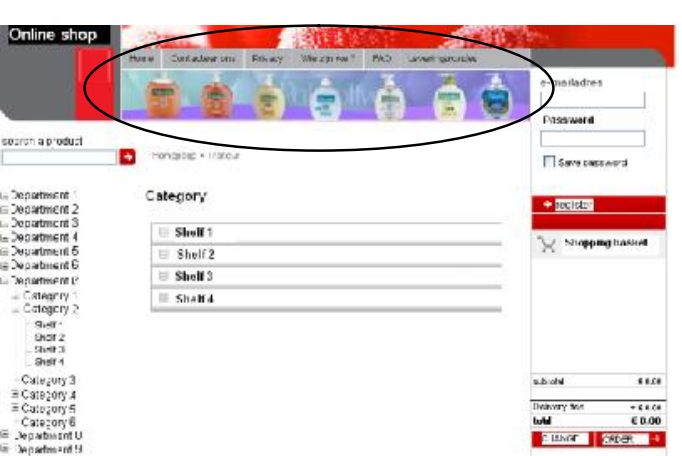

Aisle display

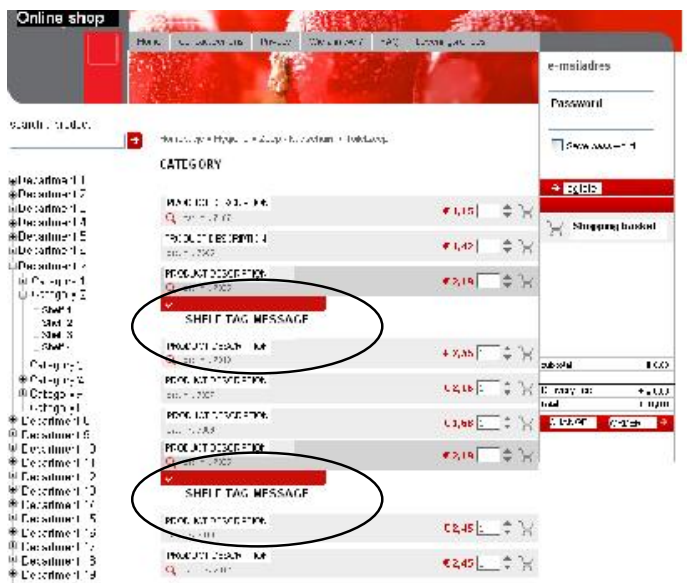

ISD Store department page

Category page

Mid-level page

Traveling/Shopping zone

Border-screen / Medium to large size

No displays for competitive brands

Several displays for competitive brands

Exclusivity

No displays for competitive brands

Immediate

Delayed (directed to brand page)

Shelf tag display

SKU list

Low-level page

Shopping zone

Mid-screen / Small size

Immediate

opportunity 


\section{Appendix B: Quasi-Elasticities}

We use the percentage change in brand market share caused by ISD as an approximate measure of ISD elasticities, because first screen (FS) and aisle (Aisle) displays are included as dummy variables in our model. Based on Equations 2-7, we derive the percentage change in brand b's market share at time $\mathrm{t}\left(\Delta m_{b, t}\right)$ caused by a first screen display as:

$$
\begin{aligned}
& \Delta m_{b, t} \mid F S=\frac{m_{b, t}\left|\left(F S_{b, t}=1\right)-m_{b, t}\right|\left(F S_{b, t}=0\right)}{m_{b, t} \mid\left(F S_{b, t}=0\right)}=\left(\frac{m_{b, t} \mid\left(F S_{b, t}=1\right)}{m_{b, t} \mid\left(F S_{b, t}=0\right)}\right)-1 \\
& =\left(\exp \left(\beta_{F S, u}\right) * \frac{\exp \left[(1-\sigma)^{*} \log \left[\left(1-m_{s b, t}\right)+m_{s b, t} * \exp \left(\beta_{F S, l}\right)\right]\right.}{\left(1-m_{b, t}\right)+m_{b, t} * \exp \left[\left(\beta_{F S, u}\right)+(1-\sigma) * \log \left[\left(1-m_{s b, t}\right)+m_{s b, t} * \exp \left(\beta_{F S, l}\right)\right] \mid\right]-1}\right.
\end{aligned}
$$

and the percentage change in brand b's market share at time t caused by an aisle display as:

$$
\begin{aligned}
& \Delta m_{b, t} \mid \text { Aisle }=\frac{m_{b, t} \mid\left(\text { Aisle }_{b, t}=1\right)-m_{b, t} \mid\left(\text { Aisle }_{b, t}=0\right)}{m_{b, t} \mid\left(\text { Aisle }_{b, t}=0\right)}=\left(\frac{m_{b, t} \mid\left(\text { Aisle }_{b, t}=1\right)}{m_{b, t} \mid\left(\text { Aisle }_{b, t}=0\right)}\right)-1 \\
& =\left(\exp \left(\beta_{\text {Aisle }, u}\right) * \frac{1}{\left(1-m_{b, t}\right)+\exp \left(\beta_{\text {Aisle }, u}\right) * m_{b, t}}\right)-1,
\end{aligned}
$$

where

$m s_{b, t}=$ market share of brand $\mathrm{b}$ at time $\mathrm{t}$;

$m s_{s b, t}=$ market share of SKU s of brand $\mathrm{b}$ at time $\mathrm{t}$;

$F S_{b, t}=$ first screen dummy variable equal to 1 if there is a first screen display for brand $\mathrm{b}$ at time $\mathrm{t}$ and 0 otherwise;

Aisle $_{b, t}=$ aisle display dummy variable equal to 1 if there is an aisle display for brand $\mathrm{b}$ at time $\mathrm{t}$ and 0 otherwise;

$\beta_{F S, u}=$ response parameter for the first screen dummy variable in the higher (upper, brand) level of the hierarchical market share model;

$\beta_{F S, l}=$ response parameter for the first screen dummy variable in the lower (SKU) level of the hierarchical market share model;

$\beta_{\text {Aisleu }}=$ response parameter for the aisle display dummy variable in the higher (upper, brand) level of the hierarchical market share model; and $(1-\sigma)=$ response parameter for the inclusive value variable. 


\section{REFERENCES}

Ailawadi, Kusum L., J.P. Beauchamp, Naveen Donthu, Dinesh K. Gauri, and Venkatesh Shankar (2009), “Communication and Promotion Decisions in Retailing: A Review and Directions for Future Research," Journal of Retailing, 85 (1): 42-55.

Anderson, Eric and Duncan T. Simester (2001). “Are Sales Signs Less Effective When More Products Have Them?" Marketing Science, 20 (2): 121-143.

Andrews, Rick L. and Imran S. Currim (2004). "Behavioral Differences between Consumers Attracted to Shopping Online versus Traditional Supermarkets: Implications for Enterprise Design and Marketing Strategy," International Journal of Internet Marketing and Advertising, 1 (1): 38-61.

Arnold, Mark J. and Kristy E. Reynolds (2009). “Affect and Retail Shopping Behavior: Understanding the Role of Mood Regulation and Regulatory Focus," Journal of Retailing, 85 (3): 308-320.

Babin, Barry J. and William R. Darden (1995). "Consumer Self-Regulation in a Retail Environment," Journal of Retailing, 71 (1): 47-70.

Bakos, Yannis (2001). “The Emerging Landscape for Retail E-Commerce,” Journal of Economic Perspectives, 15 (1): 69-80.

Bell, David R., Jeongwen Chian, and V. Padmanabhan (1999). "The Decomposition of Promotional Response: An Empirical Generalization,” Marketing Science, 18 (4): 504526.

Bemmaor, Albert C. and Dominique Mouchoux (1991). "Measuring the Short-Term Effect of In-Store Promotion and Retail Advertising on Brand Sales: A Factorial Experiment," Journal of Marketing Research, 28 (2): 202-214.

Breugelmans, Els, Katia Campo, and Els Gijsbrechts (2007). "Shelf Sequence and Proximity Effects on Online Grocery Choices," Marketing Letters, 18 (1/2): 117-133. 
Chan, Tat, Chakravarthi Narasimhan, and Qin Zhang (2008). “Decomposing Promotional Effects with a Dynamic Structural Model of Flexible Consumption," Journal of Marketing Research, 45 (4): 487-498.

Chandon, Pierre, Wesley J. Hutchinson, Eric Bradlow, and Scott H. Young (2009). "Does InStore Marketing Work? Effects of the Number and Position of Shelf Facings on Brand Attention and Evaluation at the Point of Purchase," Journal of Marketing, 73 (6): 1-17.

Childers, Terry J., Christoper L. Carr, Joann Peck, and Stephen Carson (2001). “Hedonic and Utilitarian Motivations for Online Retail Shopping Behavior,” Journal of Retailing, 77 (4): 511-536.

Cho, Chang-Hoan and Hongsik, J. Cheon (2004). "Why Do People Avoid Advertising on the Internet," Journal of Advertising, 33 (4): 89-97.

Chu, Junhong, Pradeep Chintagunta, and Javier Cebollada (2008). “A Comparison of WithinHousehold Price Sensitivity Across Online and Offline Channels,” Marketing Science, 27 (2): 283-299.

Cohen, Jacob (1977). Statistical Power Analysis for the Behavioral Sciences (revised edition). New York: Academic Press.

Degeratu, Alexandru M., Arvind Rangaswamy, and Jianan Wu (2000). “Consumer Choice Behavior in Online and Traditional Supermarkets: The Effects of Brand Name, Price, and Other Search Attributes," International Journal of Research in Marketing, 17 (1): 55-78. DelVecchio, Devon, Shanker H. Krishnan, and Daniel C. Smith (2007). “Cents or Percent? The Effects of Promotion Framing on Price Expectations and Choice," Journal of Marketing, 71 (3): 158-170.

DelVecchio, Devon, Arun Lakshmanan, and Shanker H. Krishnan (2009). “The Effects of Discount Location and Frame on Consumers' Price Estimates," Journal of Retailing, 85 (3): $336-346$. 
Dhar, Sanjay K., Stephen J. Hoch, and Nanda Kumar (2001). "Effective Category

Management Depends on the Role of the Category," Journal of Retailing, 77 (2): 165184.

Donovan, Robert J. and John R. Rossiter (1982). “Store Atmosphere: An Environmental Psychology Approach,” Journal of Retailing, 58 (1): 34-58.

Drèze, Xavier and Stephen J. Hoch (1998). "Exploiting the Installed Base Using CrossMerchandising and Category Destination Programs," International Journal of Research in Marketing, 15 (5): 459-471.

East, Robert, Vicki Eftichiadou, and Michael Williamson (2003). "Research Note: Point-ofPurchase Display and Brand Sales," International Review of Retail, Distribution and Consumer Research, 13(1): 127-135.

Foekens, Eijte W., Peter S.H. Leeflang, and Dick R. Wittink (1997). “Hierarchical versus Other Market Share Models for Markets with Many Items," International Journal of Research in Marketing, 14 (4): 359-378.

Ganesh, Jaishankar, Kristy E. Reynolds, Michael Luckett, and Nadia Pomirleanu (2010). “Online Shopper Motivations, and e-Store Attributes: An Examination of Online Patronage Behavior and Shopper Typologies,” Journal of Retailing, 86 (1): 106-115.

Gijsbrechts, Els, Katia Campo, and Tom Goossens (2003). “The Impact of Store Flyers on Store Traffic and Store Sales: A Geo-Marketing Approach," Journal of Retailing, 79 (1): $1-16$.

Grewal, Dhruv and Michael Levy (2007). "Retailing Research: Past, Present and Future,” Journal of Retailing, 83 (4): 447-464.

Grewal, Dhruv and Michael Levy (2009). “Emerging Issues in Retailing Research,” Journal of Retailing, 85 (4): 522-526. 
Hanssens, Dominique M., Leonard J. Parsons, and Randall L. Schultz (2001). Market Response Models: Econometric and Time Series Analysis, Boston/Dordrecht/London: Kluwer Academic Publishers.

Hoyer, Wayne D. and Deborah J. MacInnis (2010). Consumer Behavior, $5^{\text {th }}$ Edition, Mason: South-Western CENGAGE Learning.

Inman, Jeffrey J., Leigh McAlister, and Wayne D. Hoyer (1990). “Promotion Signal: Proxy for a Price Cut?” Journal of Consumer Research, 17 (1): 74-81.

Keller, Kevin L. (1991). "Memory and Evaluation Effects in Competitive Advertising Environments," Journal of Consumer Research, 17 (4): 463-476.

Kukar-Kinney, Monika, Nancy M. Ridgway, and Kent B. Monroe (2009). “The Relationship Between Consumers' Tendencies to Buy Compulsively and Their Motivations to Shop and Buy on the Internet," Journal of Retailing, 85 (3): 298-307.

Konus, Umut, Peter Verhoef and Scott Neslin (2008). "Multichannel Shopper Segments and Their Covariates," Journal of Retailing, 84(4): 398-413.

Laroche, Michel, Zhiyong Yang, Gordon H.G. McDougall, and Jasmin Bergeron (2005). "Internet versus Bricks-and-Mortar Retailers: An Investigation into Intangibility and its Consequences," Journal of Retailing, 81 (4): 251-267.

Larson, Jeffrey S., Eric Bradlow, and Peter S. Fader (2005). “An Exploratory Look at Supermarket Shopping Paths," International Journal of Research in Marketing, 22 (4): 395-414.

Leeflang, Peter S. H., Dick R. Wittink, Michel Wedel, and Phillipe A. Naert (2000). Building Models for Marketing Decisions. Dordrecht/Boston: Kluwer Academic Publishers.

Liljenwall, Robert (2004). The Power of Point-of-Purchase Advertising: Marketing at Retail. Washington, DC: Point-of-Purchase Advertising International. 
McKinnon, Gary F., Patrick J. Kelly, and Robison E. Doyle (1981). "Sales Effects of Pointof-Purchase In-Store Signing," Journal of Retailing, 57 (2): 49-63.

Prud'homme, Andrea and Kenneth K. Boyer (2005). “A Comparison of In-Store vs. Online Grocery Customers," Grocery E-Commerce: Consumer Behavior and Business Strategies. Niels Kornum and Mogens Bjerre, eds. Cornwall, UK: MPG Books Ltd., 79-96. Rosenthal, Robert (1991). Meta Analytic Procedures for Social Research, Applied Social Research Methods Series. Beverly Hills, CA: Sage Publications.

Schröder, Hendrik and Silvia Zaharia (2008). "Linking Multi-Channel Customer Behavior with Shopping Motives," Journal of Retailing and Consumer Services, 15 (6): 452-468. Spaeth, Jim (2004). “Post-Promotion Evaluation,” Point of Purchase Advertising International. [Available at http://www.allbusiness.com/retail-trade/4250967-1.html.] Tellis, Gerard J. (1998). Advertising and Sales Promotion Strategy. Reading, MA: AddisonWesley.

Verhoef, Peter C. and Fred Langerak (2001). "Possible Determinants of Consumers' Adoption of Electronic Grocery Shopping in The Netherlands," Journal of Retailing and Consumer Services, 8 (5): 275-285.

Vrechopoulos, Adam P., Robert M. O’Keefee, Georgios I. Doukidis, and George J. Siomkos (2004). "Virtual Store Layout: An Experimental Comparison in the Context of Grocery Retail," Journal of Retailing, 80 (1): 13-23.

Wilkinson, J.B, Barry J. Mason, and Christie H. Paksoy (1982). “Assessing the Impact of Short-Term Supermarket Strategy Variables," Journal of Marketing Research, 19 (1): 72 86.

Wolf, Fredric (1986). Meta Analysis: Quantitative Methods for Research Synthesis. Beverly Hills, CA: Sage Publications. 
$\mathrm{Xu}$, Yunjie (Calvin) and Kim Hee-Woong (2008). “Order Effect and Vendor Inspection in Online Comparison Shopping," Journal of Retailing, 84 (4): 477-486.

Zhang, Jie and Lakshman Krishnamurthi (2004). "Customizing Promotions in Online Stores," Marketing Science, 23 (4): 561-578.

Zhang, Jie and Michel Wedel (2009). "The Effectiveness of Customized Promotions in Online and Offline Stores,” Journal of Marketing Research, 46 (2): 190-206. 